\title{
Investigation of the Relationship between Organizational Intelligence and Strategic Thinking and Determination of Its Role in Creation of a Mindful Organization: A Case Study Research
}

\author{
Bahareh Torkamani* \\ Master of Business Administration (MBA), Payame Noor University of Tehran, Iran \\ Mohammad Mahmoudi Maymand \\ Associated Professor of Department of Business Administration \& MBA, Payame Noor University \\ PO Box 19395-3697 Tehran, Iran; *Corresponding author: torkamani22@yahoo.com
}

\section{Doi:10.5901/mjss.2016.v7n3s2p79}

\begin{abstract}
Nowadays, organizational intelligence (OI) is considered to be an organization's competitive advantage and potential for achieving its goals. The present study aimed to investigate the relationship between organizational intelligence and strategic thinking and to determine its role in creation of a mindful organization. In this descriptive, applied survey research, the study population included all the staff and managers of Sepah Bank in Shiraz, Iran. At first, a 220-subject sample size was determined for the study that, according to Cochran's formula, was decreased to 140 subjects. The study participants were selected through simple random sampling. The study data were collected using a researcher-made questionnaire, which consisted of Albrecht's standard questionnaire (2003) and a questionnaire based on Goldman's strategic thinking model (2005). It should be noted that the reliability and validity of the questionnaire was approved before its final distribution. Then, the data were analyzed using SmartPLS software. In order to measure organizational intelligence, the researchers made use of Albrecht's model, which included the following dimensions: strategic vision, shared fate, appetite for change, heart, alignment and congruence, knowledge deployment, and performance pressure. The study results revealed a significant relationship between organizational intelligence and strategic thinking. Also, significant relationships were observed between all the Ol variables and strategic thinking variable. Therefore, it can be suggested that focusing on $\mathrm{Ol}$ and strategic thinking and improving these factors in a banking system can be a background for mindfulness resulting in better organizational performance.
\end{abstract}

Keywords: Organizational intelligence, Strategic thinking, Mindful organization, Organizational mindfulness, Banking System

\section{Introduction}

Organizations management is faced with new challenges, which cannot be responded by previous strategies based on the past teachings and experiences. To date, managers believe that in order to progress, they should seek for changes to maintain their stability against the ever-changing environmental conditions. Therefore, using smart methods seems to be necessary in this regard (Pahlavanian, 2007). Recent studies have indicated that organizational intelligence is one of the features that an organization should have for successful performance in today's competitive world.

In the recent years, due to the complicated and non-linear changes in the business world, organizations need different types of managers. In this respect, in addition to technical and managerial capabilities, concepts such as organizational intelligence and strategic thinking, as personal skills, play a critical role in reaching organizational vision and goals. In other words, organizations with smarter managers are more capable of achieving opportunities. It seems that the combination of managerial knowledge, organizational intelligence, and strategic thinking can help staff and managers identify weaknesses and strengths and achieve organizational goals (Stalinski, 2004).

Based on the researches performed in the recent years, organizational intelligence is an effective factor in some organizational components, such as creativity (Ebrahimifard, 2014), organizational agility (Porkiani, Hejinipoor, 2013), staff performance (Marjani, Soheilipour, 2012), learning, and knowledge management, indicating the importance of organizational intelligence. Since organizational intelligence and strategic thinking are based on creative and divergent thinking that occurs in the brain's right hemisphere and are among the key features of strategist managers, they are probably related to each other (Henley, 2006). By identifying and strengthening this relationship and presenting strategies 
in this area, an organization can be changed into a mindful organization, eventually resulting in competitive advantage. Therefore, the present study aims to investigate the relationship between organizational intelligence and strategic thinking, which has been less taken into account in the banking system. In other words, this research aims to find the answer to the following question: "What kind of relationship is there between organizational intelligence and strategic thinking".

\section{Literature Review}

Considering environmental changes, organizational intelligence can help organizations conform to these changes by creating and using knowledge and guarantee their conformity to the strategic environment by reconfiguration (Halal, 1998; Schwaninger, 2003). On the other hand, lack of organizational intelligence may lead to unawareness or incorrect understanding of the environment, resulting in slow responsiveness in organizations (Veryard, 2012). In case organizations are not highly responsive to environmental changes, they cannot continue their activity in a competitive setting. Therefore, one of the impacts of organizational intelligence is agility in organizations (Porkiani, Hejinipoor, 2013).

Organizational intelligence contains all information, experiences, knowledge, and perception of organizational issues (Simic, 2005). In fact, by focusing on knowledge and learning, organizational intelligence can lead to creation of an intelligent organization (Albrecht, 2003). In case an organization tends towards mindfulness, it will achieve competitive advantage in the long time. Yet, production of creative solutions, creation of marketing performance advantage, and fast responsiveness are only a part of the advantages of an organization with high organizational intelligence. On the other hand, the concept of strategic thinking entered the field of strategic organizational concepts more than a decade ago. Strategic thinking is considered to be one of the main characteristics of efficient managers (Collins, 2000). In fact, strategic thinking provides staff and organizations with an insight of the present conditions so that they can best benefit from their opportunities.

In 2001, Weick and Sutcliffe presented the organizational mindfulness model, which refers to an organization that has less internal conflict and can perceive operational complexities. Organizational mindfulness is defined as the extent of attention an organization pays to specific details of emerging threats. It also involves quick responsiveness to these details (Weick et al., 1999; Weick and Sutcliffe, 2001). In the organizational mindfulness model, managers notify their staff about mindfulness and stimulate them to act more mindfully (Vogus and Sutcliffe, 2012). According to Ray et al. (2011), organizational mindfulness emerges when leaders encourage culture of rich thinking and paying attention to performance capacity. Furthermore, organizational mindfulness and mindful organizing are followed by strategic and operational advantages.

Mindful organization is in fact a reaction to modern organization, which involves complicated technologies, is hard to understand for human operators, and is prone to unpredictable and unpreventable incidents. Therefore, members of an organization maintain their sensitivity towards operations and stay concordant with the progress of events. These aspects of a mindful approach to organizational performance cause members to have a deep understanding of issues, resulting in timely action and finding solutions in case of problems. Since mindful organization has been designed for preventing huge problems, it can tolerate errors and change them into a learning experience. Moreover, creation of mindful decisions is transferred to the most qualified members of the organization, irrespective of their hierarchical ranks. This is somewhat similar to human's autonomous nervous system. Although the brain is the central location of intelligence, it involves smart behaviors and other body organs also learn to conduct the learned behaviors if necessary. This identifies the relationship between intelligence and a mindful organization. In fact, a mindful organization can be regarded as a location for development of emergent innovation strategies (Travica, 2015). Instead of a clear objective, planning and leadership, an emergent strategy includes various interactional objectives and players. An emergent strategy has its roots in measures that change into a stable pattern over time, irrespective of particular goals (Mintzberg, 1978). Quantitative and qualitative evidences have demonstrated that organizational mindfulness is associated with reliability and safety and is effective in organizational opportunities (Vogus \& Sutcliffe, 2012). Mindfulness can pave the way for innovation in various fields, including product development, organizational changes, and customer relationships. Hence, mindfulness in organization can be considered to be a dimension of organizational intelligence (Travica, 2015).

With a closer look on the present conditions ruling the global business, one can understand that the competitive world has changed into a game whose goal is selecting an individual who can create the best ideas with a strategic vision. In this respect, instead of wasting their energy for predicting future problems, organizations spend their time and energy on reaction to unexpected problems and changes. This vicious cycle locks an organization in a passive situation, which is an incorrect process. While encountering such situations, the concept of strategic thinking emerges for filling the gaps and overcoming restrictions created by strategic planning. Thus, organization's managers and staff should be 
creative strategic thinkers rather than strategic planners, because plans tend to change normally. In fact, strategic thinking aims to maintain goals stability and to direct the erratic path of organizations towards demands (Bouhali et al., 2015).

What follows includes some researches conducted in this area.

Bob Travica (2015) from the University of Manitoba conducted a study entitled "modeling organizational intelligence: no search engine is like Google" in which, he theorized organizational intelligence and introduced a model of organizational intelligence incorporating traditional assumptions about organization and environment into a new framework. The results of that study indicated how organizational intelligence was embedded in particular aspects of organization, individual and group cognition, Google technology, and management, as it was seen in sustainable product innovation and organizational performance.

Ercetin, Potas et al. (2010) performed a study to assess multi-dimensional organizational intelligence for determining organizational and managerial capabilities of educational institutes in Turkey. In that study, the researchers made use of the multi-dimensional organizational intelligence scale designed by Ercetin and Potas, which included seven dimensions. The results revealed a moderate level of organizational intelligence. Besides, no significant difference was observed among various areas regarding the perception of organizational intelligence. However, a significant difference was found between teachers and managers in this respect.

Younghan Jung (2009) from the University of Virginia focused on an approach for management of organizational intelligence. He sought for a model for organizational intelligence and aimed to define OI as a combination of knowledge and skills in organizations. The results of his investigation demonstrated that Ol, as a new approach, was capable of improving organizational activities through successful decision-making process.

Kazemian et al (2015) studied the relation between organizational intelligence and customer relationship management among the staff of a health center. The results showed that improvement of relation between manager and personnel can support personnel's creativity that can improve customer relationship management.

\section{Research's Conceptual Model}

The conceptual model in the present research determines the relationship between the Albrecht's organizational intelligence, its seven dimensions and strategic thinking. The overall research structure has been presented in the following figure:

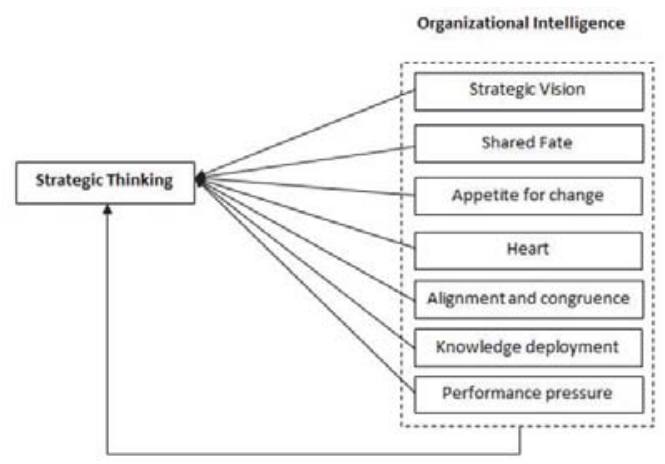

Figure 1. Research's Conceptual Model

The conceptual definitions of the present research have been briefly explained in the following table:

Table 1. Research's conceptual definitions

\begin{tabular}{|l|l|l|}
\hline 1 & Strategic vision & $\begin{array}{l}\text { lny organization needs a theory, concept, or principle. Strategic vision assumes that leaders have the ability } \\
\text { to express, deduce, and recreate the concept of success (Albrecht, 2003). }\end{array}$ \\
\hline 2 & $\begin{array}{l}\text { In case staff and members consider themselves to be a part of the organizational system and have a correct } \\
\text { understating of the organizational mission, they know that they contribute to the organization's success. } \\
\text { Hence, their efforts for achieving organizational goals and missions increase synergistically (Albrecht, 2003). }\end{array}$ \\
\hline
\end{tabular}




\begin{tabular}{|l|l|l|}
\hline 3 & Appetite for change & $\begin{array}{l}\text { Organizations show different reactions to changes. Some organizations resist changes, some accept them, } \\
\text { and some consider them to be a challenge for obtaining new experiences and discovering opportunities } \\
\text { (Albrecht, 2003). }\end{array}$ \\
\hline 4 & Heart & Tendency towards voluntary attempts beyond an organization's standards (Albrecht, 2003). \\
\hline 5 & $\begin{array}{l}\text { Alignment and } \\
\text { congruence }\end{array}$ & $\begin{array}{l}\text { Unexpressed policies, norms, values, and expectations beside laws and regulations can help the organization } \\
\text { achieve its goals (Albrecht, 2003). }\end{array}$ \\
\hline 6 & Knowledge deployment & $\begin{array}{l}\text { Refers to creation, modification, organization, and sharing knowledge. Organizational intelligence should } \\
\text { guarantee free knowledge deployment in the culture (Albrecht, 2003). }\end{array}$ \\
\hline 7 & Performance pressure & $\begin{array}{l}\text { Any individual has the ability to select performance; feeling of achieving something and believing in its } \\
\text { accuracy. Performance pressure is most effective when an organization is accepted by its members as a } \\
\text { wanted set of mutual expectations and an obligatory operation for common success (Karl Albrecht, 2003). }\end{array}$ \\
\hline 8 & $\begin{array}{l}\text { Strategic thinking } \\
\text { creative Thinking is a nonlinear thinking tool that improves the performance of an organization by finding }\end{array}$ \\
\hline
\end{tabular}

\subsection{Research Hypotheses}

\section{Main hypothesis}

- Organizational intelligence is related to strategic thinking.

Subsidiary hypotheses

1- Strategic vision is related to strategic thinking.

2- Shared fate is related to strategic thinking.

3- Appetite for change is related to strategic thinking.

4- Heart is related to strategic thinking.

5- Knowledge deployment is related to strategic thinking.

6- Alignment and congruence is related to strategic thinking.

7- Performance pressure is related to strategic thinking.

\subsection{Research Methodology}

In the present descriptive, applied survey research, the statistical community included all the managers and staff of Sepah Bank in Shiraz, Iran. At first, a 220-subject sample size was determined for the study that, according to Cochran's formula, was decreased to 140 subjects. The study participants were selected through simple random sampling. The study data were collected using a researcher-made questionnaire containing demographic characteristics and some questions about the research hypotheses. This questionnaire was a combination of Albrecht's Ol questionnaire (2003) and Goldman's strategic thinking questionnaire (2005) whose reliability and validity were approved. The validity of the questionnaire was confirmed by professors of management. Besides, its reliability was assessed by the SPSS statistical software, and the Cronbach's alpha coefficient for the whole questionnaire was 0.805 .

In order to analyze the data, at first, the study participants' demographic characteristics, including sex, education level, age, and working experience were described. Then, the research hypotheses and conceptual model were analyzed through structural equation modeling using SmartPLS software.

\section{Findings and Results}

Considering the descriptive results, none of the study participants was below 25 years old, 23 (16.4\%) were 25-35 years old, 62 (44.3\%) were 36-45 years old and 55 (39.3\%) were over 45 years old. In addition, $65 \%$ and $35 \%$ of the participants were male and female, respectively. With respect to education level, none of the participants had PhD and below diploma degrees, 105 (75\%) had bachelor's degrees, and 35 (25\%) had master's degrees. Moreover, 7 (7\%), 53 (37.8\%), 60 (42.9\%), and 20 (14.3\%) participants had below 7, 8-15, 16-21, and above 21 years of working experience, respectively.

Before final analysis, the data were screened to determine their reliability. In this regard, accuracy of data registration, existence of lost data, normality, and existence of collinearity among the variables were evaluated. According to the results, not much correlation was found among the study variables. In other words, no collinearity was observed among the constructs (study variables), indicating lack of redundant information. 
Table 2. Correlation coefficients

\begin{tabular}{lcccccccc} 
& 1 & 2 & 3 & 4 & 5 & 6 & 7 & 8 \\
Knowledge Deployment & 1 & & & & & & & \\
Strategic Vision & 0.405 & 1 & & & & & & \\
Heart & 0.530 & 0.357 & 1 & & & & & \\
Alignment and Congruence & 0.486 & 0.165 & 0.267 & 1 & & & & \\
Performance Pressure & 0.410 & 0.155 & 0.691 & 0.357 & 1 & & & \\
Appetite for Change & 0.383 & 0.462 & 0.382 & 0.484 & 0.191 & 1 & & \\
Shared Fate & 0.151 & 0.479 & 0.465 & 0.372 & 0.425 & 0.484 & 1 & \\
Strategic Thinking & 0.718 & 0.225 & 0.502 & 0.466 & 0.372 & 0.488 & 0.734 & 1 \\
\hline
\end{tabular}

In order to assess the significance of model's relations, t-values were computed. In doing so, the research hypotheses were examined using path coefficients and t-values. In case t-value is higher than 1.96 for a path, the path is significant and the hypothesis is confirmed at 0.05 level. In this relation, the effect size is between 0 and 1 , with values closer to 1 representing larger effect of the independent variable on the dependent one. The results of the main hypothesis of research have been represented in the following table.

Table 3. The results of the main research hypothesis

\begin{tabular}{|c|c|c|c|c|c|}
\hline \multirow{2}{*}{ Main Hypothesis } & \multicolumn{2}{|c|}{ Variable } & Path coefficient ( $\beta)$ & t-value & Result \\
\cline { 2 - 3 } & Independent & Dependent & & & \\
\hline 1 & Ol & Strategic Thinking & 0.831 & 25.808 & Confirmed \\
\hline
\end{tabular}

Based on the PLS outputs, the results of investigation of the research hypotheses are as follows:

Considering the main research hypothesis, $t$-value $=25.808$, which is higher than the absolute value of 1.96 . This indicated that this hypothesis was confirmed at 0.95 confidence level. In other words, organizational intelligence is related to strategic thinking. Besides, the effect size of this relationship was 0.831 , which indicated the significant direct effect of organizational intelligence on strategic thinking.

The results of assessment of the subsidiary hypotheses have been represented in the following table.

Table 4. The results of the sub-hypotheses

\begin{tabular}{|c|c|c|c|c|c|}
\hline \multirow{2}{*}{ Subsidiary Hypotheses } & \multicolumn{2}{|l|}{ Variable } & \multirow{2}{*}{ Path coefficient $(\beta)$} & \multirow[b]{2}{*}{ t-value } & \multirow{2}{*}{ Result } \\
\hline & Independent & Dependent & & & \\
\hline 1 & Strategic vision & Strategic thinking & 0.203 & 2.110 & Confirmed \\
\hline 2 & Shared fate & & 0.419 & 8.376 & Confirmed \\
\hline 3 & Appetite for change & & 0.159 & 4.019 & Confirmed \\
\hline 4 & Heart & & 0.329 & 8.502 & Confirmed \\
\hline 5 & Knowledge deployment & & 0.078 & 2.529 & Confirmed \\
\hline 6 & Alignment and congruence & & 0.883 & 13.261 & Confirmed \\
\hline 7 & Performance pressure & & 0.309 & 5.994 & Confirmed \\
\hline
\end{tabular}

As the table depicts, the results of partial least squares modeling indicated that t-values of the subsidiary hypotheses 1,2 , $3,4,5,6$, and 7 were higher than the absolute value of 1.96 , confirming all the hypotheses at 0.95 confidence level. Thus, all the components of organizational intelligence (strategic vision, shared fate, appetite for change, heart, knowledge deployment, alignment and congruence, and performance pressure) are associated with strategic thinking. Moreover, alignment and congruence, shared fate, and heart showed the most significant relationships with strategic thinking.

In order to confirm the reliability of the structural model, $\mathrm{R}^{2}$ and $\mathrm{Q}^{2}$ indices were utilized and the results have been presented in the following table.

Table 5. $\mathrm{R}^{2}$ and $\mathrm{Q}^{2}$

\begin{tabular}{lcc}
\hline Variable & $\mathbf{Q}^{2}>\mathbf{0 . 1 5}$ & $\mathbf{R}^{\mathbf{2}}>\mathbf{0 . 1 9}$ \\
\hline Strategic Thinking & 0.213 & 0.689 \\
\hline
\end{tabular}


In the end, the overall Goodness of Fit (GOF) of the model was evaluated. In this regard, this model based on least partial squares use GOF index, which should be higher than 0.3. This index was also calculated for the present model and indicated its appropriate fit which showed in the following.

$\mathrm{GOF}=\sqrt{\text { Communalities } \times R^{2}}=0.560$

\section{Discussion and Conclusion}

The present study aimed to investigate the relationship between organizational intelligence and strategic thinking in the banking system and to determine its role in creation of mindfulness in organization. The research population included 140 managers and staff of Sepah Bank in Shiraz, Iran. This study assessed the relationship between the seven indicators of organizational intelligence of Karl Albrecht's model and strategic thinking. The results revealed a significant positive relationship between organizational intelligence and strategic thinking. This was in agreement with the results obtained by Pourroostaei et al. (2015), Yaghoubi et al. (2013), Bob Travica (2015), Albrecht (2010), and Younghan Jung (2009). The results were also in line with those of the study conducted by Albrecht that showed $\mathrm{Ol}$ as an effective factor in other organizational and managerial factors. Moreover, among the seven dimensions of $\mathrm{OI}$, alignment and congruence showed the largest effect on strategic thinking. However, Rahmani et al. (2013) reported that heart had the strongest relationship with strategic thinking.

In the current study, alignment and congruence followed by shared fate had the most significant relationships with strategic thinking. Considering the concept of alignment and congruence, obeying the laws and regulations in the banking system is expected to have a key impact on reaching success, improving organizational performance, and saving resources. Additionally, shared fate emphasizes that in case staff consider themselves to be a part of the organization, organizational performance can be improved. Therefore, bank managers have to take measures to empower positive attitude towards the organization. In order to strengthen the feeling of shared fate in the organization, they can involve staff in important programs and their outcomes, because this causes all the members to do their best to help managers achieve organizational goals.

The process of changing from a traditional organizational to being mindful one is an important requirement in today's organizational world. Organizational intelligence has been introduced as a factor that can direct organizations towards organizational mindfulness (Travica, 2015). Therefore, it can be claimed that increasing managers' and staff's organizational intelligence in a banking system can provide the ground for changing into mindful organizations, resulting in better performance in competitive markets. Moreover, understanding of strategic situations requires creative managers with high organizational intelligence. Thus, focusing on Ol seems to be a proper solution for managers of the banking system to improve the organization's performance. This is due to the fact that managers and staff with appropriate organizational intelligence have a better understanding of customers' needs and expectations, which leads to improvement of customer relationship management (Kazemian et al., 2015). Overall, focusing on organizational intelligence and strategic thinking, empowering their relationship and creation of a mindful organization may result in benefitting from opportunities more efficiently.

\section{References}

Albrecht, K. (2002), Organizational intelligence and knowledge management the executive perspective. Retrieved from: http://www.karl Albrecht.com

Bouhali, Ratiba; Mekdad, Yousra; Lebsir, Hind; Ferkha, Linda (2015), Leader Roles for Innovation: Strategic Thinking and Planning, 3rd International Conference on Leadership, Technology and Innovation Management, Procedia - Social and Behavioral Sciences 181 (2015) $72-78$.

Collins DB, Lowe JS, Arnett CR, (2000), High- Performance Leadership at the Organization Level, Advances in Developing Human Resources. 18: 19-46.

Ebrahimi Fard, Shahrbano. (2014), The relationship between organizational intelligence and employees' creativity, International Journal of Management and Humanity Sciences. Vol., 3 (S2), 2540-2545, 2014, ISSN 2322-424X.

Erçetin, ŞŞ., Potas, N. et al., (2010), Using multi-dimensional organizational intelligence measurements to determine the institutional and managerial capacities of technical education institutions for girls. African Journal of Business Management Vol.5 (27), pp. 1125611264, 9 November, 2011.

Goldman, Ellen. (2010), Strategic Thinking at the Top, MIT Sloan Management Review 48, no. 4 (2007): 75.

Halal, William. (2006), Organizational intelligence, knowledge management review, issue 1 march 1998.

Haycock, Ken (2011), Strategic Thinking: Lessons for Leadership from the Literature, Library Leadership \& Management Vol. 26, No. $3 / 4$.

Henley, William. (2006), Strategic Planning: Left-Brain or Right-Brain - Rethinking it, retrieved from: https://www.apwa.net/Resources/ 
Reporter/Articles/2006/12/Strategic-Planning-Left-Brain-or-Right-Brain--Rethinking-it

Jung, Younghan.(2009), An Approach to Organizational Intelligence Management (A Framework for Analyzing Organizational Intelligence Within the Construction Process).

Marjani, Amir Babak; Soheilipour, Mojdeh. (2012). The Relationship between Organizational Intelligence and Staff Performance Based on the Model of Karl Albrecht (The case of Iran Branch, China National Petroleum Company), International Journal of Business and Social Science, Vol. 3 No. 4 [Special Issue - February 2012].

Mintzberg. H. (1978). Patterns in Strategy Formation, Management Science, Vol 24, No 9, 1978, pp 934-948.

Kenichi Ohmae, The Mind of the Strategist (New York: McGraw-Hill, 1982), 13.

Pahlavanian, H. (2007), The succeed experience about strategic management usage, Yazd: Nikooravesh Publication

Porkiani, Masood; Hejinipoor, Mohsen. (2013). Studing the relationship between organizational intelligence and organizational agility in supreme audit court, European Online Journal of Natural and Social Sciences 2013; vol.2, No. 3(s), pp. 1052-1060, ISSN 18053602.

Pourroostaei, M.A., Pourkiani, M., 2015, The Study of the Effect of Organizational Intelligence on Strategic Thinking of Social Welfare Organization Employess in Yazd Province, TI Journals, International Journal of Economy, Management and Social Sciences, Vol(4), No (1), January, 2015. pp. 1-7.

Rahmani, Z., Asgharzadeh, M. 2013. The relationship between organizational intelligence and strategic thinking managers in the business environment, (Case Study: Sorkhoun and Qeshm Gas Refinery Company), First National Conference on Business Management, Tehran, page 1-8.

Ray, J. L., Baker, L. T., \& Plowman, D. A. (2011), Organizational mindfulness in business schools. Academy of Management Learning and Education, 10: 188-203.

Schwaninger, M. (2003). A Cybernetic Model To Enhance Organizational Intelligence, Systems Analysis Model Simul, 2003, Vol. 43, No. 1 , pp. 53-65.

Simic, Ivana.(2005), Organizational Learning as A Component of Organizational Intelligence Information and Marketing Aspect of the Economically Development of the Balkan the Balkan Countries Journal.

Stalinski, Sherryl. (2004). Organizational Intelligence: A Systems Perspective. Organization Development Journal. Vol. 22 No. 2

Travica, Bob (2015), Modeling organizational intelligence: Nothing googles like Google, Online Journal of Applied Knowledge Management, A Publication of the International Institute for Applied Knowledge Management, Vol. 3, Issue 2, 2015.

Veryard, Richard. (2012-2013). Building Organizational Intelligence.

Vogus, T.J.; Sutcliffe, K.M., 2012, Organizational Mindfulness and Mindful Organizing: A Reconciliation and Path Forward, Academy of Management Learning \& Education, 2012, Vol. 11, No. 4, 722-735. http://dx.doi.org/10.5465/amle.2011.0002C.

Weick, K. E., Sutcliffe, K. M., \& Obstfeld, D. 1999. Organizing for high reliability: Processes of collective mindfulness. In B. M. Staw \& L. L. Cummings, (Eds.), Research in organizational behavior, 21: 81-123. Greenwich, CT: JAI Press.

Weick, K. E., \& Sutcliffe, K. M. 2001. Managing the unexpected: Assuring high performance in an age of complexity. San Francisco, CA: Jossey-Bass.

Yaghoubi, N.M., Khaksar, S.M.S \& el. (2011), The relationship between Organizational Intelligence and strategic thinking, Journal of Theoretical and Applied Information Technology, 15 September 2011. Vol. 31 No. 1.

Kazemian et al., 2015. Study of Relation between Organizational Intelligence and Customer Relationship Management from Managers and Higher Education Staff and Experts Point of View, International Research Journal of Management Sciences. Vol., 3 (7), 329334, 2015, Available online at http://www.irjmsjournal.com 